\title{
Presumed hereditary retinal degenerations: Ibadan experience
}

\author{
A.O. Ashaye \\ Department of Ophthalmology, College of Medicine, \\ University of Ibadan, Ibadan, Nigeria. \\ E-mail:aashaye@skannet.com
}

\section{Summary}

Background: Retinitis pigmentosa (RP) is a hereditary retinal degenerative condition with no known treatment. Associated ocular conditions, such as cataract and glaucoma, when present further worsen vision, but these conditions are often treatable. There are, however, no known reports of cataract or glaucoma surgery in subjects with RP in Nigeria. This study describes the clinical presentation of $R P$, the prevalence of associated treatable disorders and the characteristics of patients with severe visual impairment and blindness.

Method: A retrospective review of 52 cases presumed and diagnosed to have. RP was performed on patients who presented at the Eye Clinic, University College Hospital, Ibadan over a three-year period. The cases were classified into clinical types; those with associated treatable eye conditions were identified and those with severe visual impairment and blindness were further evaluated.

Results: Retinitis pigmentosa was an uncommon clinical condition in patients who presented at the Eye Clinic being $0.69 \%(n=52)$ of a total of 7,520 new outpatients recorded during a 3-year period. Typical RP were 44 in number representing $84.0 \%$ of these cases. Those diagnosed with very early onset $R P$, with severe visual impairment and nystagmus may have been congenital Leber's amaurosis. Retinitis pigmentosa with systemic features and atypical RP were uncommon. However, $34.5 \%$ had cataract (mostly posterior subcapsular cataract), while $11.4 \%$ had high intraocular pressure and these were mostly in couched eyes. Risk factors for severe visual disability and blindness were cataract, age and secondary glaucoma as a result of couching. Conclusion: Treatable ocular conditions associated with RP are not uncommon. RP patient tend to have cataract which if neglected may result in total blindness.

Key words: Retinitis pigmentosa, Associated treatable eye conditions, Severe visual impairment, Couching.

\section{Résumé}

Introduction: Retinite pigmentaire (RP) est une maladie héréditaire dégénérative rétinienne avec aucun traitement connu. Des maladies oculaires liées, telles que la cataracte et glaucome, dans le cas ou elles sont présentes, aggravent de plus la vue, mais le plus souvent, ces maladies sont guérissables. Toutefois, il n'y a aucun rapport de la chirurgie de la cataracte ou du glaucome chez les sujets atteints du RP au Nigeria. Cette étude met en relief la présentation clinique de RP, la fréquence des troubles guérissables liés et les traits caractéristiques des patients atteints d'affaiblissement visuel grave et la cécité.

Méthodes: Un bilan rétrospectif des 52 cas présumés et diagnostiqués atteints de RP ont été opérés chez des patients qui se sont présentés à la clinique oculaire, Collège Hospitalier universitaire, Ibadan au cours d'une période de trois ans. Les cas ont été classés en types cliniques; on a vait identifié ceux liés avec des maladies oculaires guériss ıbles et ceux liés avec affaiblissement visuel grave et la cécité ont été profondement étudiés.

Résultats: Rétinite pigmentaire est une maladie clinique peu commun chez les patients qui se sont présen és au centre médical oculaire $0,69 \%(\mathrm{n}=52)$ parmi un total de 7,520 nouveaux malades qui viennent consulter à l'hôpital, enregistré au cours d'une période de 3 ans. Le nombre de RP typique était 44 ce qui constitue $84,0 \%$ de ce; cas. Ceux diagnostiqués avec la première attaque de RP atteints d'affaiblissement visuel grave, aigu et nystagmt s pourraient être amaurose congénitale de Leber. Rétinite pigmentaire avec des traits systémiques et un RP typiqu: étaint peu common. Toutefois, $34,5 \%$ étaient atteints de la cataracte (le plus souvent, cataracte sous capsulaire postéricure), tandis que $11,4 \%$ avaient hautes pression intraoculdaires principalement parmi ceux avec des yeux opérés à travers couching. Facteurs de risque pour affaiblissmen visuel aigu et cécité étaient cataracte, âge et glaucose sécondaire à la suite du couching.

Conclusion: Des maladies oculaires guérissables liéés avec RP sont courants. Des patients atteints de RP o.tt tendance à avoir la cataracte ce qui pourrait provoquer la c écité totale si on le néglige.

\section{Introduction}

Features suggestive of hereditary retinal d generation may present with different conditions. Most comı non among these is retinitis pigmentosa. Retinitis pigmentosa (RP) refers to a group of inherited diseases characterized by !, oor vision in dim light, constricted visual fields, bone-s jicule-like pigmentation of the fundus and electroretinographic evidence of photoreceptor cell dysfunction.

The disease is rare, estimated to affect about $]$ in 3,0005,000 people in different communities ${ }^{1-3}$ but there is paucity of information about this disease in Nigerians, and indeed, Africans in general. Literature search yielded little or no information about this condition in Africans.

The prognostic implications of the diagnos $s$ retinitis pigmentosa is serious and often devastating, as there is no known treatment which can reverse the visual dis ability associated with RP. Associated ocular disorders like cataracts, glaucoma and refractive errors, which are treatab e, further worsen the visual disability, even when they appe ir minor.

Genetic typing has been used to classify some variants of retinitis pigmentosa and these genetic types hive slight differences in clinical manifestations ${ }^{4,5}$. Prior to iclentifying the genetic types, clinical types were based on the presence or absence of systemic disease, typical or atypical features and age of onset ${ }^{6}$.

Unfortunately, detailed family histories are difficult to obtain and molecular genetic testing is not routinily avail- 
able for patients, likewise electroretinographic studies are generally not available in most developing countries. This study therefore sets out to determine the pattern of presentation, potential risk factors for severe visual impairment and blindness and frequency of associated treatable eye conditions of RP patients.

\section{Material and Methods}

The records of all patients diagnosed as having "retinitis pigmentosa" (RP), presenting to the Eye Clinic of the University College Hospital, Ibadan during the period January 1999 to December 2002, (3 years) were reviewed. The diagnosis of RP was clinical and was based on a history of night blindness, visual field loss and fundus changes which included attenuated retinal vessels, waxy pale optic discs and variable amount of pigment clumping in the retina. Data were collected from records using a structured questionnaire; some of the patients were personally examined by the author. The presence and types of refractive errors were ascertained by objective retinoscopy, the presence of cataracts was ascertained by slit lamp examination and intraocular pressure was measured by applanation tonometry. Disc appearance was evaluated with direct ophthalmoscopy. The presence of any one of these associated eye disorders was noted. The presence of aphakia was noted. Other data collected were age at presentation, duration of noticeable symptoms, gender, corrected visual acuity, visual fields, and the presence of associated systemic illnesses.

Patients with history of trauma, painful redness of eyes and drug ingestions like large amounts of chloroquine, phenothiazine were excluded.

The frequency distribution of each variable was produced. The Chi square statistic was employed to test the association between any two categorical variables. The 'odds ratio' and their $95 \%$ confident intervals were used to calculate the risk of blindness with the presence of certain factors.

\section{Results}

During the period of study, 7,520 new outpatients were recorded at the University College Hospital Eye Clinic. Fiftytwo subjects were diagnosed as hereditary pigmentary retinopathy, constituting $0.69 \%$ of the total number of new outpatients; while senile cataract constituted almost half of the number of patients seen (48.9\%) and glaucoma (all forms) $22.5 \%$, during the same period.

Of the 52 subjects, 8 subjects are presented separately in Table 1, because either their clinical features suggested atypical retinitis pigmentosa such as sector RP; the onset of RP occurred at very early age; or the patient had other systemic features. The details of these 8 subjects showed $5(9.6 \%)$ had very early age of onset of the disease varying between 1 year and 5 years; 2 of these also had associated nystagmus and very poor visual acuities. Another 2(3.8\%) subjects had systemic associations - one was suspected to have Usher's syndrome, while the other developed features suggestive of RP after an illness which necessistated inserting a pacemaker. His visual acuity had been $\%$ in each eye when seen one year prior to the illness and subsequent blinding eye condition. The one subject $1(1.9 \%)$ had 'sector' RP.

The remaining forty-four ( $84.6 \%$ ) patients diagnosed as RP had no systemic features but had typical ocular features of RP. The age of presentation and gender distribution of the 44 subjects are shown in Table 2 . The mean age at presenta-

Table 2 Age at presentation and sex of subjects with typical retinitis pigmentosa

\begin{tabular}{|c|c|c|c|c|c|c|}
\hline \multicolumn{7}{|c|}{ Sex } \\
\hline \multirow[t]{2}{*}{$\begin{array}{c}\Delta \text { ge of } \\
\text { presentation }\end{array}$} & \multicolumn{2}{|c|}{ Male } & \multicolumn{2}{|c|}{ Female } & \multicolumn{2}{|c|}{ Total } \\
\hline & $\mathrm{n}$ & $\%$ & $\mathrm{n}$ & $\%$ & $\mathrm{n}$ & $\%$ \\
\hline $10-19$ & 5 & 17.9 & 6 & 37.5 & 11 & 25.0 \\
\hline $20-29$ & 4 & 14.3 & 6 & 37.5 & 10 & 22.7 \\
\hline $30-39$ & 7 & 25.0 & 2 & 12.5 & 9 & 20.5 \\
\hline$\geq 40$ & 12 & 42.8 & 2 & 12.5 & 14 & 31.8 \\
\hline Total & 28 & 100.0 & 16 & 100.0 & 44 & 100.0 \\
\hline
\end{tabular}

Table 3 Demographic and clinical types of RP by age at presentation

\begin{tabular}{lccl}
\hline Age of presentation & $\leq 5 \mathrm{yrs}$ & $10-29 \mathrm{yrs}$ & $\geq 30 \mathrm{yrs}$ \\
Sample size & $\mathrm{n}=5$ & $\mathrm{n}=21$ & $\mathrm{n}=23$ \\
Mean reported age of onset & $3.2 \mathrm{yrs}$ & $11.0 \mathrm{yrs}$ & $30.5 \mathrm{yrs}$ \\
Males & $60 \%$ & $32.2 \%$ & $75.2 \%$ \\
$\%$ RVA $<\%$ & $80 \%$ & $19.0 \%$ & $34.8 \%$ \\
Cataract & $0 \%$ & $9.7 \%$ & $30.4 \%$ \\
Myopia & $\%$ & $47.7 \%$ & $34.8 \%$ \\
\hline
\end{tabular}

Table 1 Subjects with a typical hereditary retinal degenerations

\begin{tabular}{|c|c|c|c|c|c|}
\hline Patient & $\begin{array}{c}\text { Age at } \\
\text { Presentation to } \\
\text { Clinic }\end{array}$ & Sex & $\begin{array}{l}\text { Age at } \\
\text { Onset of } \\
\text { Symptoms }\end{array}$ & $\begin{array}{l}\text { Reason for atypical } \\
\text { Clinical presentation }\end{array}$ & Possible diagnosis \\
\hline 1 & 22 & F & 12 years & $\begin{array}{l}\text { Sectoral pigmentation } \\
\text { Systemic features (deafness, blindness }\end{array}$ & Sector RP \\
\hline $\begin{array}{l}2 \\
3\end{array}$ & 35 & $\mathrm{~F}$ & 20 years & $\begin{array}{l}\text { right eye from glaucoma) } \\
\text { Onset of symptoms after a }\end{array}$ & ? Usher's syndrome \\
\hline & 43 & M & 44years & $\begin{array}{l}\text { pacemaker insertion. Initial presenting } \\
\text { Visual acuity } 6 / 9 \text { each eye Visual Acuity } \\
\text { reduced to HM }\end{array}$ & $\begin{array}{l}\text { Ophthalmic artery or } \\
\text { Choroidal artery occlusion }\end{array}$ \\
\hline 4 & 22 & $\mathbf{M}$ & 5years & Early childhood onset & $\begin{array}{l}\text { ? Leber's congenital amaurosis } \\
\text { (LCA) }\end{array}$ \\
\hline 5 & 18 & $\mathrm{~F}$ & lyear & Very early onset + Nystagmus & ?Leber's (LCA) \\
\hline 6. & 19 & M & 2 years & Very early onset + Nystagmus & ?Leber's (LCA) \\
\hline 7. & 29 & $\mathrm{~F}$ & 4years & Early onset & ? Leber's (LCA) \\
\hline 8. & 23 & M & 4years & Early onset & ? Leber's (LCA) \\
\hline
\end{tabular}


Table 4 Visual acuity in the right eyes versus mean age and sex

\begin{tabular}{|c|c|c|c|c|}
\hline & & Corrected & RVA & \\
\hline $\mathrm{n}$ & $\begin{array}{c}\text { VA } \% /^{-6 / 18} \\
27\end{array}$ & $\mathrm{VA} \frac{1}{24}-6 / 60$ & $\begin{array}{c}\mathrm{VA}<0 / \text { (1) } \\
12\end{array}$ & $P$ - values \\
\hline Mean age (yrs) & $\quad 28.9$ & 31.2 & 38.2 & 0.15 \\
\hline SD & 13.2 & 7.9 & 15.7 & \\
\hline Sex & & & & \\
\hline Males & 16 & 3 & $9(32.1 \%)$ & $X^{2}=0.92$ \\
\hline Females & 11 & 2 & $3(18.7 \%)$ & $P=0.63$ \\
\hline
\end{tabular}

Table 5 Potential risk factors for blindness odd's ratio and 95\% confidence interval $(\mathrm{CI})$

\begin{tabular}{lcccc}
\hline Blindness & \multicolumn{2}{c}{ Blindness } & Odd's ratio & 95\% CI \\
No & Yes & & \\
1. Sex & & & & \\
Males & 19 & 9 & & \\
$\quad$ Females & 13 & 3 & 2.05 & $0.08-2.57$ \\
2. Associated cataract & & & & \\
$\quad$ Yes & 8 & 2 & & \\
No & 4 & 20 & 20 & $2.39-221.89$ \\
3. Associated glaucoma & & & & \\
Yes & 4 & 1 & & \\
No & 8 & 31 & 15.50 & $1.28-422.33$ \\
4. Myopia & & & & \\
$\quad$ Yes & 1 & 17 & & \\
No & 5 & 8 & 0.09 & $0.00-1.12$ \\
\hline
\end{tabular}

tion was 31.7 years ( $\mathrm{SD}=13.8$ years); the majority $28(63.6 \%)$ were males. The youngest person presented to the Eye Clinic at age 12 years and the oldest at age 60 years (Table 2 ).

Twenty-one subjects $(47.7 \%)$ presented to the Eye Clinic between the ages of 10 and 29 years (Table 3), a quarter of whom were less than 20 years. The male to female ratio of the subjects below 30 years of age presented at the clinic, was $3: 4$. The male to female ratio of those who presented at the age of 30 years and above, was 4.7 to 1 . As the age of the patient increased, the ratio of males presenting with RP to females became greater, being ratio $6: 1$ in subjects over 40 years.

Thus three clinical groups have been identified, those with typical RP who were the majority, a few with associated systemic features and those mostly found in children with very early onset of symptoms.

\section{Refraction and visual acuity}

The forty-four subjects were given a refraction examination. But 5 subjects who had lens opacities and another 5 with aphakic eyes were excluded from refraction. The remaining 34 subjects had myopia $18(52.9 \%)$, hyperopia $3(8.8 \%)$, astigmatism $8(23.5 \%)$ and $5(14.7 \%)$ had no refractive errors. The degree of myopia ranged from $-1.00 \mathrm{DS}$ to 7.00DS. The 3 subjects who were hyperopic were under 20 years.

The corrected visual acuity was $\%$ or better in $27(61.4 \%)$ right eyes and $25(56.8 \%)$ left eyes. Visual acuity less than $\%_{60}$ was found in $12(27.3 \%)$ right eyes and $11(25.0 \%)$ left eyes of subjects. A higher proportion of male patients $(32.1 \%)$ had visual acuity less than $\%$ compared to female patients (18.7\%) in their right eyes (Table 4). Also, 8 of 28 (28.6\%) male subjects had visual acuity less than $\%$ in their left eye as against 3 of $16(18.7 \%)$ female subjects. Althugh a lower proportion of females had severe visual impairment or blindness $(\mathrm{VA}<\%$ ) in their right eye compare 1 to the male counterpart (18.7\% vs $32.1 \%$ ), the association between sex and poor vision was not statistically significant at the $5 \%$ probability level. Total blindness (no light perception) was present in 3 eyes of subjects who had raised intri ocular pressure and/or aphakia.

\section{Lens opacities}

Fifteen subjects did not have their pupils dilated for lens examination and 10 of the remaining 29 subjets had lens opacification or aphakia (34.5\%). Five of these $17.2 \%)$ had varying degrees of lens opacification out of wl ich $3(60 \%)$ had posterior subcapsular opacity (PSC), 1(20\%) had cortical opacity, $1(20 \%)$ had mixed opacities. All the fi ve eyes that were aphakic were a result of couching.

\section{Intraocular pressure}

Only 5 patients (out of 44 RP subjects) (11.4\%) had intraocular pressure more than $21 \mathrm{mmHg}$; and 3 , if them had couching.

\section{Family history}

Ten subjects $(22.7 \%)$ reported a family hist ory of night blindness, $18(40.9 \%)$ had no family history of nig it blindness while $16(36.7 \%$ ) were not sure if they had a pos tive family history. A higher proportion of males had posi ive family history of night blindness $(30 \%$ vs $12.5 \%)$. A similar proportion of male to female subjects were unsure of a family history of night blindness.

\section{Potential risk factors for severe visual loss and blindness}

The risk of blindness was two-fold in a male subjects with RP. The odds ratio (OR) was 2.05 [95\% confide nce interval (CI) $0.08-2.57]$. The risk, however, was not satistically significant. But subjects with RP with associated cataract are 20 times more likely to become blind than tho:e without cataract. (OR $=20,95 \% \mathrm{CI} 2.39-221.89)$. $\mathrm{RP}$ paients with associated glaucoma have a 15 times greater risk of becoming blind $(\mathrm{OR}=15.50,95 \% \mathrm{CI} 1.28-422.33)$. The $95 \%$ confidence interval suggests that when RP is associated with cataract or glaucoma, the results are statistically significant. Myopia does not seem to be a risk factor for blindness when associated with RP. Associated cataract and aphakic glat coma are potential risk factors for blindness or severe visıltal loss in subjects with RP. These results are shown in Tabls 5 .

\section{Discussion}

Retinitis pigmentosa (RP) and other retinal de renerative conditions are not commonly seen as the Eye Clinic of the University College Hospital (UCH) Ibadan comparid to other causes of severe visual impairment and blindnes:, cataract and glaucoma.

The diagnosis of RP in this study without EF G is presumptive, but the clinical features of patients see 1 here do not differ from those seen in other parts of the wo $\mathrm{ld}^{1-4}$.

Three distinct groups have been identified bas ed on the clinical presentation. First group are the majority cf the sub- 
jects who had typical features of RP; then a number of subjects who had systemic features and those subjects whose symptoms started very early in life, some of the latter had nystagmus and all had severe visual disability. The presence of nystagmus suggests that some of the subjects may have had Leber's congenital amaurosis (LCA). Nystagmus distinguishes LCA from early onset $\mathrm{RP}^{7}$.

More males with RP than females were seen at the Eye Clinic, constituting $63.6 \%$ of cases. Older male patients (over 30 years) who presented in the hospital Eye Clinic, outnumbered females in the same age group by 5 to 1 . It is suggested that male preponderance may due to the excess contribution of sex linked RP.

Myopia, which is found in association with RP, was common in all age groups - up to 7.00DS in some cases similar to findings in other reports ${ }^{1}$, or may be a bias for selection.

The prevalence of cataract and aphakia in subjects with typical RP was $34.5 \%$ in this series of cases.

Although this is within reported values ${ }^{7}$ it may be lower than the actual prevalence of cataract in the subjects with RP seen in this study because of the non-standardization of lens examination by different observers. The posterior subcapsular cataract was the most common form of cataract in RP patients. This has also been found in other studies ${ }^{8}$. All the aphakic eyes seen had couching. In Africa, traditional doctors may use couching, irrespective of the cause of condition which caused the patient to become blind ${ }^{9}$. High intraocular pressure (IOP) was a feature associated more with eyes of subjects with RP who have had couching. Of the eyes with high IOP, two did not have couching done. Severe visual disability was a common feature in the eyes with aphakia, aphakic glaucoma, cataract and those with long standing RP. Subjects with severe loss of visual acuity were likely to be older, although the difference in mean age of subjects who have good, moderate and poor visual acuities was not statistically significant at the $5 \%$ probability level. This may be due to the small sample size. The majority of patients with severe visual impairment, who had cataract or aphakia and secondary glaucoma, were male. Male subjects also presented with a two-fold risk of becoming blind (although the association was not statistically significant); but this could also be because of the small sample size. In addition the male subjects studied presented at an older age and blindness is known to increase with age.

The risk of blindness in subjects with RP is high when cataract and or glaucoma are present. The risks are manifold and unlikely to be due to chance. The bias for severe cases can be attributed to the fact that such cases were more likely to be referred to a University Teaching Hospital where this study was carried out. Although RP may cause severe visual disability, it does not usually lead to total loss of vision. In this RP study group only those who had couching had lost their vision completely, the eyes had no light perception.

Cataract is a recognized associated ocular feature of all types of RP. Patients may develop lens opacities at a relatively young age. The location, PSC in most cases, further worsens the visual disability even if it appears as minor opacity. The removal of such cataracts have been found to yield fairly good results ${ }^{10 !}$. Lens surgery by couching, however, has worsened the vision in the group of patients in the present study.

Of the major hereditary types, sex-linked RP has the earliest onset of presentation ${ }^{1}$. Many patients who have early onset RP usually become severely visually disabled by the age of 30 years. The earlier the onset of RP, the worse the vision $^{11}$. This may partly account for the high proportion of visual disability in males seen in this study. Some of those with severe visual disability may also be those with autosomal recessive RP. It was also found that those who could recall a family history of night blindness were predominantly males. The unreliability of family history makes interpretation of this finding difficult.

Subjects presenting with atypical RP, i.e., sector RP were rare one-22-year old female. Another patient who noticed poor vision after a pacemaker insertion may have acquire retinal degeneration. The 35-year-old woman who had RP with deafness and glaucoma may have Usher's syndrome.

\section{Conclusion}

Presumed hereditary retinal degeneration is not common in patients presenting to the Eye Clinic of University College Hospital (UCH) Ibadan. Refractive errors, cataract and less commonly glaucoma are associated treatable eye conditions found in these patients, as have been found in similar studies. However, those patients who had couching done resulting in aphakia, aphakic glaucoma had more severe visual impairment and blindness. This could be avoided as cataract extraction in subjects with RP have been found in some studies to lead to improved visual acuity. Couching performed in subjects with RP makes their visual disability more.

\section{Acknowledgement}

Prof. Bamgboye for his contribution during the preparation of this manuscript and Miss Olivia Sunday for typing it.

\section{References}

1. Kimura AE, Drack AV and Stone E.M: Retinitis Pigmentosa and associated disorders. In Wright K.W., ed. Paediatric Ophthalmology and Strabismus, St. Louis; CV Mosby Co; 1995.

4. Berson EL., Rosner B and Simon off E: Risk Factors for genetic typing and detection in retinitis pigmentosa. Am J. Ophthalmol 1980; 89:763-75.

5. Fishman GA: Retinitis pigmentosa: genetic percentages. Arch Ophthalmol 1978; 96:822-6.

6. Haim $M$ and Rosenberg $\mathrm{T}$ : Retinitis Pigmentosa and allied disorders in Denmark IV. Ophthalmic features in systemic and non-systemic cases. Acta Ophthal (Cobenh) 1993; Oct, 71: 597-605.

7. Heher KL, Traboulsi EL and Maumence IH. The natural history of Leber's congenital amaurosis: age-related findings in 35 patients. Ophthalmology, 1992; 99:241-245.

8. Fishman GA, Anderson JR and Lourenco P: Prevalence of posterior subcapsular lens opacities in patients with retinitis pigmentosa. Brit. J. Ophthalmol 1985; 69:263-266.

9. Bastel JV, Heckenlively JR and Straatsma BR: Cataract Sur- 
gery in retinitis pigmentosa. Ophthalmology 1982; 89: 880-4.

10. Goyal $\mathrm{M}$ and Hogeweg $\mathrm{M}$ : Couching and cataract extraction. A clinic based study in Northern Nigeria. Community Eye
Health Journal. 1998; 19: 6-7.

11. Grover S, Fishman GA, Alexander KR, et al: Visual acuity impairment in patients with retiniti; pigmentosa. Ophthalmology 1996; 103:1593-1600. 